\title{
The iron- and temperature-regulated haemolysin YhIA is a virulence factor of Yersinia ruckeri
}

\begin{abstract}
Correspondence
José A. Guijarro

jaga@fq.uniovi.es
\end{abstract}

Received 6 July 2006

Revised 27 September 2006

Accepted 25 October 2006
Lucía Fernández, ${ }^{1}$ Miguel Prieto ${ }^{2}$ and José A. Guijarro ${ }^{1}$

\author{
1'Área de Microbiología, Departamento de Biología Funcional, Facultad de Medicina, IUBA, \\ Universidad de Oviedo, 33006 Oviedo, Asturias, Spain \\ ${ }^{2}$ Laboratorio de Sanidad Animal de Jove, Serida, 33299 Gijón, Asturias, Spain
}

\section{INTRODUCTION}

The Gram-negative bacterium Yersinia ruckeri is the aetiological agent of the enteric redmouth disease, which affects mainly salmonid fish. Despite the general administration of a quite effective vaccine, outbreaks still occur, produced mainly by certain strains (Austin et al., 2003; Fouz et al., 2006). Therefore, this pathology continues to cause important economic losses in the aquaculture industry in many countries.

Early work showed that some extracellular products of $Y$. ruckeri, including several enzymic activities such as protease, lipase and haemolysin, may play an important role in the development of pathogenesis. Romalde \& Toranzo (1993) observed that the injection of these products into fish reproduced some characteristic symptoms of yersiniosis such as haemorrhages in the mouth and intestine. Nevertheless, it was only recently that several studies started

Abbreviation: IVET, in vivo expression technology.

The GenBank/EMBL/DDBJ accession number for the sequences reported in this paper is AY576533. to shed light on the specific pathogenicity mechanisms of the enteric redmouth bacterium. For example, it has been demonstrated that the protease Yrp1, produced by the socalled $\mathrm{Azo}^{+}$strains, as well as ruckerbactin, a catecholate siderophore, are involved in virulence (Fernández et al., 2002, 2003, 2004).

With the aim of achieving a better understanding of the precise virulence factors possessed by this micro-organism, Fernández et al. (2004) used an in vivo expression technology (IVET) system to identify genes induced during the infection of fish by $Y$. ruckeri, which would very likely be related to virulence. This technique allowed the identification of 14 different in vivo-induced (ivi) genetic loci. One of these ivi genes encodes a protein putatively involved in the secretion and activation of a Serratia-type haemolysin (Fernández et al., 2004). It is well known that haemolysins participate in the pathogenicity of Gram-positive and Gram-negative bacteria and that they sometimes also show a cytolytic activity against different types of nucleated cells. For this reason, it seemed interesting to carry out further analyses on this in vivo-induced haemolysin. 
This paper reports the study of two genes required for the production of an in vivo-induced extracellular cytolysin named YhlA, concerning its regulation by temperature and iron, transcriptional analysis, implication in virulence and cytotoxicity, and presence in $Y$. ruckeri strains of different origins.

\section{METHODS}

Bacterial strains, plasmids and growth conditions. The bacterial strains and plasmids used in this study are listed in Table 1. Escherichia coli strains were routinely grown in $2 \times$ TY (tryptone/ yeast extract) broth and agar, and Y. ruckeri strains in nutrient broth (NB) and agar (NA) (Pronadisa). When required, the following compounds were added to the media: $100 \mu \mathrm{g}$ ampicillin $\mathrm{ml}^{-1}, 50 \mu \mathrm{g}$ rifampicin $\mathrm{ml}^{-1}, 100 \mu \mathrm{g} 2,2^{\prime}$-dipyridyl $\mathrm{ml}^{-1}$ or $100 \mu \mathrm{g} \mathrm{FeCl}_{3} \mathrm{ml}^{-1}$, all of them from Sigma Aldrich. Liquid cultures were incubated at $37^{\circ} \mathrm{C}$ for E. coli and $18^{\circ} \mathrm{C}$ or $28^{\circ} \mathrm{C}$ for Y. ruckeri in orbital shakers at 250 r.p.m. Growth was monitored by determining the $\mathrm{OD}_{600}$ at different times during incubation and bacterial concentrations were determined by serial dilutions and plate counts. Experiments on regulation of gene expression were performed using minimal medium M9, prepared as described by Romalde et al. (1991). All the glassware needed for the preparation of this medium was previously treated with $1 \mathrm{M} \mathrm{HCl}$ to remove iron traces and rinsed with doubledistilled water.

Genetic techniques. DNA isolation and manipulation were performed as described by Sambrook \& Russell (2001). Phage T4 DNA ligase and calf intestinal alkaline phosphatase were purchased from Roche, restriction enzymes from Amersham Pharmacia Biotech, DNA polymerase from Biotools, and oligonucleotides from Sigma Aldrich.
Nucleic acid sequencing was performed by the dideoxy chaintermination method with the DR Terminator kit (Applied Biosystems) in an ABI Prism 310A automated DNA sequencer from Perkin-Elmer at the Universidad de Oviedo facilities. The sequences obtained were analysed with the computer program BLASTX.

The sequence adjacent to the partial fragment of $y h l B$ present in clone $i v i V$ was obtained by inverse PCR. Briefly, genomic DNA from $Y$. ruckeri 150 was digested with ClaI or SalI, and the generated fragments were religated. The ligation mixture was then used as template DNA for a PCR, using the Long Amplification kit (Biotools) and oligonucleotides corresponding to the known DNA sequence. The reaction was performed in a Perkin-Elmer 9700 GeneAmp thermocycler.

RT-PCR. Total RNA was obtained from $3 \mathrm{ml}$ late-exponential-phase cultures of parental strain 150R and mutant 150R $y$ hlB grown in M9 supplemented with 2,2'-dipyridyl. RNA was isolated using an RNeasy mini kit (Qiagen) and was treated with RNase-free DNase (Promega) to eliminate traces of DNA. Reverse transcription (RT)PCRs were performed using Superscript One-Step with Platinum Taq (Invitrogen Life Technologies); 20 ng RNA was used in each reaction. Control PCRs using DNA polymerase (Biotools) were performed to determine whether RNA was free of contaminant DNA. The primers used were: A1, 5'-ATATCCGGGCCGAAGGC-3' (nt 911 to 927 of $y h l A$ ) and A2, 5'-ATTGTCGATCAATAAGC-3' (nt 1848 to 1832 of $y h l A$ ), for yhlA (938 bp); B1, 5'ATAACCGGTGGAGATCA-3' (nt 472 to 488 of $y$ hlB) and B2, 5'CAGGTTATGAGTGCGGT-3' (nt 1206 to 1190 of $y h l B$ ), for $y h l B$ (735 bp); BA1, 5'-GCAGAATACTTTATCGC-3' (nt 1430 to 1447 of $y h l B$ ) and BA2, 5'-GCTGAAGGTGTCACAAT-3' (nt 185 to 169 of $y h l A$ ), for a region overlapping $y h l B$ and $y h l A$ (510 bp); and O1, 5' ACAGGCAAATTATGGAC-3' (nt 8 to 24 of orf 1 ) and O2, 5'TTATCAACTGGGGTTCA-3' (nt 298 to 282 of orf1), for the ORF located downstream of $y$ hlA (293 bp).

Table 1. Bacterial strains and plasmids

All the Y. ruckeri strains belong to serotype O1, the most virulent, except 956, which belongs to serotype O2.

\begin{tabular}{|c|c|c|}
\hline Strain or plasmid & Characteristics & Source or reference \\
\hline \multicolumn{3}{|l|}{ Yersinia ruckeri } \\
\hline $146,147,148,149,150$ & Trout-isolated virulent strains (Danish fish farms) & J. L. Larsen (University of Frederiksberg, Denmark) \\
\hline $35 / 85,13 / 86$ & $\begin{array}{l}\text { Trout-isolated virulent strains (Danish and UK } \\
\text { fish farms, respectively) }\end{array}$ & C. J. Rodgers (University of Tarragona, Spain) \\
\hline 955 (11.4), 956 (11.29), 43/19 & Trout-isolated virulent strains (USA fish farms) & CECT (Spanish Type Culture Collection) \\
\hline $\mathrm{Al} 00, \mathrm{Al} 02$ & Trout-isolated virulent strains (Spanish fish farms) & $\begin{array}{l}\text { I. Márquez (Laboratory of Animal Health, } \\
\text { Asturias, Spain) }\end{array}$ \\
\hline $150 \mathrm{R}$ & Rif $^{\mathrm{r}}$ derivative of 150 & Fernández et al. (2002) \\
\hline 150RiviV & $\begin{array}{l}\text { Strain containing fusion between } y h l B \text { promoter } \\
\text { and } l a c Z Y\end{array}$ & Fernández et al. (2004) \\
\hline 150R $y h l A$ & Rif $^{\mathrm{r}} y h l A::$ IVET8 Ap $^{\mathrm{r}}$ & This study \\
\hline 150R $y h l B$ & Rif $^{\mathrm{r}} y h l B::$ pIVET8 $A p^{\mathrm{r}}$ & This study \\
\hline \multicolumn{3}{|l|}{ Escherichia coli } \\
\hline SM10ipir & $\begin{array}{l}\text { thi thr leu tonA lacY supE recA::RP4-2-Tc:: Mu } \\
\mathrm{Km}: \text { : } \lambda \text { pir }\end{array}$ & Simon et al. (1983) \\
\hline \multicolumn{3}{|l|}{ Plasmids } \\
\hline pIVET8 & $\mathrm{Ap}^{\mathrm{r}}$, oriR6K, $\mathrm{mob}^{+}$ & Mahan et al. (1995) \\
\hline pLPY5 & pIVET8:: BglII $(y h l A)$, Ap $^{\mathrm{r}}$ & This study \\
\hline pLPY6 & pIVET8:: BglII $(y h l B)$, Ap $^{\mathrm{r}}$ & This study \\
\hline
\end{tabular}


In vitro regulation analysis. For promoter expression studies, $Y$. ruckeri 150RiviV was grown in M9 supplemented with either $\mathrm{FeCl}_{3}$ or 2,2'-dipyridyl. To determine the influence of temperature, cells were incubated at $18{ }^{\circ} \mathrm{C}$ or $28^{\circ} \mathrm{C}$. Samples from stationary-phase cultures, under these conditions, were collected and their $\beta$-galactosidase activity measured as described by Miller (1972). The results were then submitted to an analysis of variance test and $P$ values $<0.05$ were considered significant.

Construction of insertion mutants. Internal fragments of the predicted ORFs of $y h l B(735 \mathrm{bp})$ and $y h l A(938 \mathrm{bp})$ were amplified by PCR with the following primers: forward primers yhlB1 and yhlA1 (5'-GCAGAGATCTATAACCGGTGGAGATCA-3', nt 472 to 488 in bold type, and 5'-GTCAAGATCTATATCCGGGCCGAAGGC-3', nt 911 to 927 in bold type), respectively, and reverse primers yhlB2 and yhlA2 (5'-CTGTAGATCTCAGGTTATGAGTGCGGT-3', nt 1206 to 1190 in bold type, and $5^{\prime}$ GACCAGATCTATTGTCGATCAATAAGC-3', nt 1848 to 1832 in bold type), respectively. All primers contained a BglII site (in italics) and four additional bases at their $5^{\prime}$ end. The generated amplicons were digested with BglII and ligated into pIVET8, previously digested with the same enzyme and dephosphorylated. The ligation mixture was utilized to transform by electroporation competent cells of E. coli SM10ipir.

Clones containing the vector with each insert were used to transfer the recombinant plasmids to $Y$. ruckeri $150 \mathrm{R}$ by filter mating, as described by Fernández et al. (2002). The mutation of the target gene in the transconjugants was verified by Southern blot analysis. Probe labelling, hybridization and developing were performed with the DIG DNA labelling and detection kit from Roche, following the manufacturer's instructions. To check that gene interruption had taken place as expected, DNA from the mutant and parental strains was prepared and digested with $B a m \mathrm{HI}$ or $\mathrm{ClaI}$ for $y h l B$ and $y h l A$, respectively. After separation of the restriction fragments in an agarose gel, these were transferred to a nylon membrane and hybridized with probes corresponding to each gene. This digestion produced bands of approximately 10 and $4 \mathrm{~kb}$ in the $y h l A$ mutant strain and 14 and $4.5 \mathrm{~kb}$ in the $y h l B$ mutant when hybridizing with the respective digoxigenin-labelled probes, instead of the 4 and $16 \mathrm{~kb}$ single fragments that appear, respectively, in the parental strain. Since pIVET8 contains internal BamHI and ClaI sites (Fig. 1), these patterns of hybridization demonstrated that plasmid pLPY5 or pLPY6 (Table 1) harbouring internal fragments of $y h l A$ or $y h l B$, respectively, was integrated in the chromosome by a single crossover event and, therefore, that the desired mutations had occurred.
Phenotypic characterization of the mutant strains. Mutant clones were tested for production of haemolytic activity, using defibrinated sheep blood (Biomedics SL) as described for Photorhabdus luminescens (Brillard et al., 2002), as well as for their ability to grow in $\mathrm{M} 9$ supplemented with either $\mathrm{FeCl}_{3}$ or 2,2'-dipyridyl. To determine the involvement of haemolysin production in virulence, $50 \%$ lethal dose $\left(L_{50}\right)$ experiments with the parental and the mutant strains were carried out as described by Fernández et al. (2002). The doses injected ranged from 10 to $10^{7}$ c.f.u. per fish and mortalities were followed up for 7 days. The $\mathrm{LD}_{50}$ values were calculated by the method of Reed \& Muench (1938). Additionally, the cytotoxicity of the mutant and parental strains was studied using cultures of the BF-2 (blue gill fry) fish cell line. Cell cultures were grown in 24-well plates at $16^{\circ} \mathrm{C}$ in Tagle medium (Sigma) supplemented with $1 \%$ $(\mathrm{w} / \mathrm{v}) \mathrm{NaHCO}_{3}$ and $10 \%(\mathrm{v} / \mathrm{v})$ bovine fetal serum. Bacterial cultures were grown in M9 medium with 2,2'-dipyridyl. Before inoculation, bacterial cells were washed three times with PBS. The inoculation was carried out in a $1: 1$ proportion $\left(5 \times 10^{5}\right.$ bacterial cells to each well containing $5 \times 10^{5}$ eukaryotic cells, approximately, as determined with a haemocytometer). Control wells were inoculated with PBS. After $48 \mathrm{~h}$ incubation at $18^{\circ} \mathrm{C}$, the cultures were observed with a Zeiss Axiovert 200M inverted microscope.

PCR detection of $y$ hIB and $y h / A$ in different $Y$. ruckeri strains. The production of haemolytic activity in cultures of $12 \mathrm{Y}$. ruckeri strains was examined following the method described above (Brillard et al., 2002). The primers used for the detection of $y$ hlB and $y h l A$ genes were as above.

\section{RESULTS AND DISCUSSION}

\section{Sequence analysis of the $y$ hIBA loci}

The application of IVET technology to Y. ruckeri led to the identification of 14 different clones, carrying in vivoinduced transcriptional fusions between $Y$. ruckeri promoters and the promoterless cat and lacZY genes (Fernández et al., 2004). The analysis of one of these clones, Y. ruckeri 150RiviV, revealed the presence of the initial $292 \mathrm{nt}$ of an ORF, encoding a protein putatively involved in the activation and secretion of a Serratia-type haemolysin (Fig. 1). In order to examine more closely the function of this toxin throughout the infectious process by Y. ruckeri,

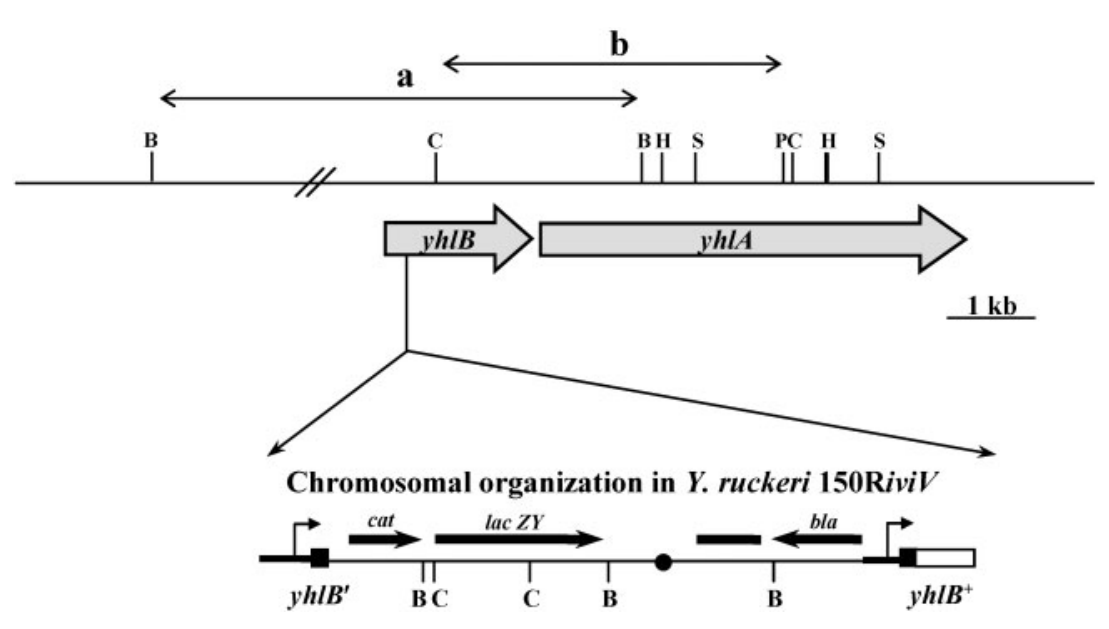

Fig. 1. Chromosomal arrangement and restriction map of the region containing genes $y h / B$ and $y h / A$ in $Y$. ruckeri 150. The organization of the transcriptional fusion between the $y$ h/B promoter and lacZY in $Y$. ruckeri 150RiviV is represented from its insertion point in $y h / B$. Arrows indicate the direction of transcription. C, Clal; B, BamHI; H, Hindlll; S, Sall; P, Pstl; a, 16 kb BamHI fragment hybridizing with $y$ h/B probe; $b$, $4 \mathrm{~kb}$ Clal fragment hybridizing with $y h / A$ probe; $y h / B^{\prime}$, initial $292 \mathrm{nt}$ of $y h / B$ gene; $y h / B^{+}$, complete copy of $y h / B$ gene; cat, chloramphenicol acetyltransferase gene (promoterless); lacZY, genes for lactose fermentation (promoterless); bla, ampicillin resistance gene. 
the adjacent region of this genetic locus was amplified by means of inverse PCR. This technique, and subsequent DNA sequencing, allowed the identification of two genes thought necessary for the production of the haemolysin (Fig. 1).

The upstream gene, named $y h l B$, consists of $1686 \mathrm{bp}$ and encodes a protein of 561 amino acids which shares a high identity with ShlB from Serratia marcescens (65\%) (Poole et al., 1988), PhlB from P. luminescens (59\%) (Brillard et al., 2002) and a putative haemolysin activation protein from Yersinia pestis CO92 (51\%) (CAC93188). According to the SignalP program, the protein YhlB carries a signal peptide of 18 amino acids. In addition, the analysis of its amino acid sequence with the program PSLPred, which predicts the subcellular location of proteins, suggested that YhlB would be probably located in the outer membrane. This is in agreement with the secretory function of these proteins, being necessary for the transport of the respective toxins through the outer membrane as well as for their activation during this process (Schönherr et al., 1993).

Another ORF, of $4893 \mathrm{bp}$, designated $y h l A$, was found $69 \mathrm{bp}$ downstream of $y h l B$. The product of this gene has high sequence identity with haemolysins of the Serratia-type pore-forming toxins. The identity was 52, 48 and $45 \%$ with the haemolysins ShlA from S. marcescens (Poole et al., 1988) and PhlA from P. luminescens (Brillard et al., 2002), and a hypothetical protein from $Y$. pestis CO92 (NP_407172), respectively. These toxins typically have a large molecular size and are secreted to the extracellular milieu by means of a type $\mathrm{V}$ or two-partner secretion system (TPSS). The deduced amino acid sequence has a putative signal peptide of 30 amino acid residues and contains the conserved motifs which are characteristic of this kind of protein: QLAG (92 to 95), ILNEV (111 to 115), NPNG (140 to 143), CGFIN (149 to 153 ), LWGNP (159 to 164), WGGIGG (553 to 558) and LQGT (1259 to 1262) (Hirono et al., 1997). According to Schönherr et al. (1993), the most relevant motif is NPNG, which seems to be involved in the secretion of the haemolysin as well as in the exertion of the haemolytic activity. These toxins bind to the membrane of erythrocytes and other cell types and are able to create pores. In addition, they have been related to invasive properties (Hertle et al., 1999). Interestingly, these haemolysins have also been found in genomic analyses of other Yersinia species, though their function is still to be determined (Deng et al., 2002; Chain et al., 2004). Therefore, as far as we know, this is the first study on the role of this group of toxins in the genus Yersinia.

\section{Transcriptional analysis}

RT-PCRs were carried out to confirm the prediction made by sequence analysis that genes $y h l B$ and $y h l A$ form an operon. The results obtained with this analysis are represented in Fig. 2 and show that a region overlapping the two genes can be amplified when using RNA from the parental strain and, therefore, that $y h l B$ and $y h l A$ are cotranscribed (Fig. 2b). On the other hand, the fact that no mRNA corresponding to $y h l A$ or to the overlapping region is present in the mutant Y. ruckeri 150RyhlB reveals that this mutation has a polar effect (Fig. 2c). However, the gene located downstream of $y h l A$, orfl, is expressed in both the parental and the mutant strains, which demonstrates that it is not affected by the interruption of $y$ hlB (Fig. 2b, c). This operon structure also occurs for genes encoding other Serratia-type haemolysins such as PhlA from $P$. luminescens (Brillard et al., 2002), although it is not a general rule. For example, the genes responsible for the production of the EthA haemolysin from Edwardsiella tarda are transcribed independently (Hirono et al., 1997).

\section{Regulation of the $y$ hlB promoter by iron and temperature}

Since $y h l B$ and $y h l A$ form a single transcriptional unit, regulation analysis was only performed on the $5^{\prime}$-upstream region of $y h l B A$. The strain Y. ruckeri 150RiviV, obtained by IVET, contains a transcriptional fusion between the $y \mathrm{hlB}$ promoter and the lacZY genes (Fig. 1), which was used to study the regulation of the expression of this gene in response to two important environmental signals, namely iron and temperature. These factors are well studied, given

(a)
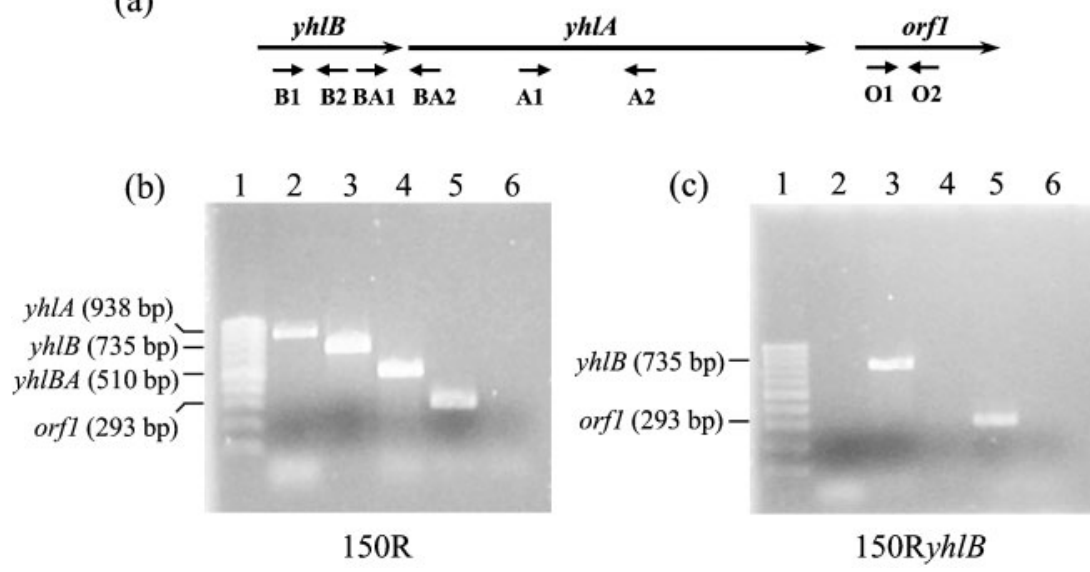

Fig. 2. RT-PCR analysis of $y h / B$ and $y h / A$ and the ORF located downstream of $y h / A$. (a) Positions of the primers used within the $y h / B, y h / A$ and orf1 genes. (b, c) RT-PCRs using RNA from $Y$. ruckeri $150 \mathrm{R}$ (b) and $150 \mathrm{R} y$ hIB (c). The following primers were used: lanes 2, A1 and A2; lanes 3, B1 and B2; lanes 4, BA1 and BA2; lanes 5, O1 and $\mathrm{O} 2$; lanes 6 , control reaction with Biotools DNA polymerase. Lanes 1, molecular size markers from 1000 to $100 \mathrm{bp}$. 
the significance they have for the pathogen to sense the transition into the host, which generally involves a change in temperature and a limitation in the amount of accessible iron (Mekalanos, 1992). Studies on the regulation of Serratia-type haemolysins have demonstrated the role of iron availability in regulation of expression (Hirono et al., 1997; Brillard et al., 2002). The influence of temperature, however, is still to be determined.

The results obtained by the determination of $\beta$-galactosidase activity in cultures grown in different conditions showed that both iron and temperature exert an important influence on the transcription levels of $y h l B$, which is repressed by iron and induced by temperature downshift. Thus, the levels of $\beta$-galactosidase activity (expressed as $A_{420} \mathrm{ml}^{-1} \mathrm{~min}^{-1}$ per $\mathrm{OD}_{600}$ unit) were $0.47 \pm 0.03,2.83 \pm 0.21$ and $4.9 \pm 0.20$ when the cells were incubated in M9 supplemented with $\mathrm{FeCl}_{3}$, M9 and M9 supplemented with 2,2'-dipyridyl, respectively $(P=0.002)$. This induction under ironrestricted conditions also occurred with the haemolysins produced by S. marcescens (Schiebel et al., 1989), P. luminescens (Brillard et al., 2002) and Ed. tarda (Hirono et al., 1997). These results agree with the hypothesis that haemolysin production might be a way of releasing iron from erythrocytes so that it can be used by the bacterial cell (Litwin \& Calderwood, 1993). In addition, the expression from the $y$ hlB promoter was approximately sevenfold higher at $18{ }^{\circ} \mathrm{C}\left(2.83 \pm 0.21 A_{420} \mathrm{ml}^{-1} \mathrm{~min}^{-1}\right.$ per $\mathrm{OD}_{600}$ unit $)$, the infection temperature, than at $28^{\circ} \mathrm{C}\left(0.42 \pm 0.11 A_{420} \mathrm{ml}^{-1}\right.$ $\min ^{-1}$ per $\mathrm{OD}_{600}$ unit), the optimal growth temperature of this micro-organism $(P=0.003)$. This matches the results obtained for gene regulation of the protease Yrp1 and ruckerbactin production (Fernández et al., 2003, 2004) and reinforces the importance of temperature as an environmental signal regulating the virulence of $Y$. ruckeri. The temperature-dependent modulation of virulence genes tends to trigger the expression of these in conditions mimicking those encountered in the host. This is not, however, a general rule and each case must be analysed independently. In the case of the genus Yersinia, the regulation of virulence genes by temperature is a wellcharacterized phenomenon (Straley \& Perry, 1995; Konkel \& Tilly, 2000).

\section{Phenotypic characterization and virulence determination of strains with mutations in $y \mathrm{~h} / \mathrm{B}$ and $y h I A$}

Independent mutations in $y h l B$ and $y h l A$ were generated (as described in Methods) to allow studies on the function and importance of the haemolysin, YhlA, in Y. ruckeri.

The haemolytic activity of YhlA was barely detectable in blood agar plates, as with other haemolysins of this type (Braun et al., 1985; Brillard et al., 2002). This phenomenon could be a consequence of the low diffusion of these proteins into the culture medium due to their high molecular mass and/or to the adherence of the protein to the cell surface. For this reason, haemolytic activity was measured using liquid cultures corresponding to the parental (150R) and the mutant strains (150RyhlA and 150RyhlB) (Table 1). Two independent experiments showed that, under the assayed conditions, the percentage of lysed erythrocytes was $41.5 \pm 6 \%, 21.7 \pm 4 \%$ and $6.6 \pm 1 \%$ for Y. ruckeri $150 \mathrm{R}$, Y. ruckeri 150R $y$ hlA and Y. ruckeri 150R $y$ hlB supernatants, respectively.

The growth of the $y h l A$ and $y h l B$ mutant strains was not retarded relative to that of the parental strain, in either ironrich or iron-depleted conditions (data not shown). This indicates that the mutations do not cause any defect in the growth ability and, therefore, that the differences in virulence could be due to the specific involvement of these proteins in the in vivo conditions. In some cases, the production of haemolysins has been related to the metabolism of iron in the cell, which implies that their main function would be the release of the iron bound to the haem group of erythrocytes (Poole et al., 1988).

Once the main characteristics of the mutant strains in vitro had been analysed, their behaviour in a fish infection model and in cell cultures was studied. $\mathrm{LD}_{50}$ experiments indicated that the mutant strains are attenuated in their virulence, because the values obtained with Y. ruckeri 150R $y h l A$ and $Y$. ruckeri $150 \mathrm{R} y \mathrm{hlB}$ were approximately 10 - and 100 -fold higher, respectively, than those of the parental strain. Thus, the means of the $\mathrm{LD}_{50}$ values obtained for the parental strain, mutant $y h l A$ and mutant $y h l B$ were $2.7 \times 10^{4}$, $3.9 \times 10^{5}$ and $3 \times 10^{6}$ c.f.u. per fish, respectively. This relationship between haemolytic activity and virulence was not found in other fish pathogens such as Edwardsiella ictaluri (Williams \& Lawrence, 2005). Cytotoxicity assays demonstrated that the deficient production of the haemolysin YhlA, caused by the mutations, led to a significant reduction of the cytopathic effects produced by this Y. ruckeri. Thus, microscopic analysis of BF-2 cell cultures infected with the mutant and parental strains revealed that only the latter was able to lyse the eukaryotic cells after 2 days incubation, whereas the tissue organization remained unaltered not only in the control wells inoculated with PBS, but also in the wells infected with the mutant strains (data not shown). This cytotoxic effect has already been demonstrated for other haemolysins of this type produced by micro-organisms such as Haemophilus ducreyi (Palmer et al., 1996), Ed. tarda (Strauss et al., 1997) and S. marcescens (Hertle et al., 1999).

\section{Presence of $y h / B$ and $y h I A$ in $Y$. ruckeri strains of different origins}

By using the liquid culture assay, previously described for the analysis of mutant strains, the supernatants of $12 \mathrm{Y}$. ruckeri strains from different sources were tested for the production of haemolytic activity. All of them showed the ability to lyse erythrocytes, with percentages of lysis ranging from 40 to $75 \%$. Likewise, all the strains gave a positive result in the PCR detection analysis of genes $y h l B$ and $y h l A$ (Fig. 3), in which the amplification of two bands of 735 and 


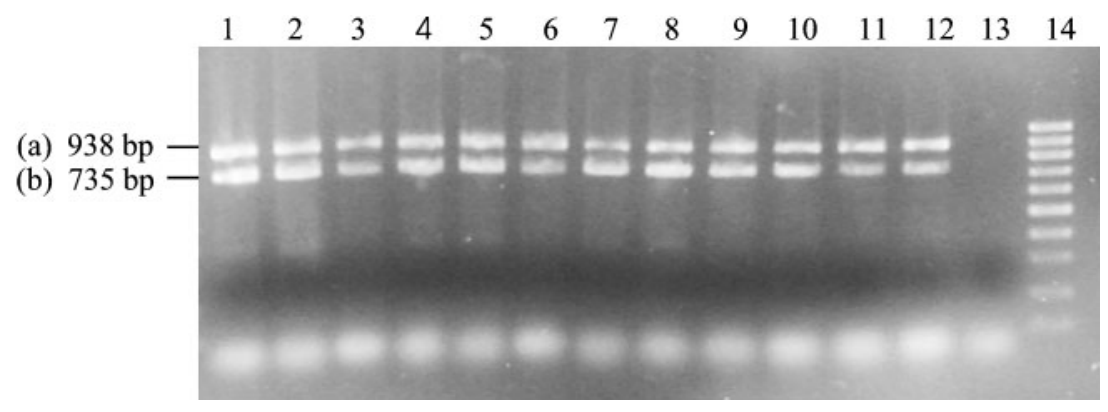

Fig. 3. $P C R$ detection of $y h / A$ and $y h / B$ in $12 Y$. ruckeri strains of different origins. After incubating the strains in NB medium, two different PCR reactions were performed. The fragments obtained were mixed and separated in $1.5 \%$ agarose gel. The amplicons generated were (a) yhlA (938 bp) and (b) $y h / B$ (735 bp). The strains corresponding to each lane are: 1,$146 ; 2,147 ; 3,148 ; 4$, $149 ; 5,150 ; 6,13 / 86 ; 7,35 / 85 ; 8,43 / 19$; 9,$955 ; 10,956 ; 11, \mathrm{Al00} ; 12, \mathrm{Al0} 2 ; 13$, negative control; 14 , molecular size markers from 1000 to $100 \mathrm{bp}$.

$938 \mathrm{bp}$, respectively, indicated the presence of these two genes. This result confirms that Y. ruckeri is a highly homogeneous species at the genetic level, as several authors have pointed out before on the basis of fingerprinting (Romalde et al., 1993) and multilocus sequence typing (Kotetishvili et al., 2005) analyses. The results obtained by Fernández et al. $(2003,2004)$ also showed that all the strains tested harbour the genes necessary for the production of the protease Yrp1 and the siderophore ruckerbactin.

\section{Conclusion}

According to the data obtained in the present work, it can be concluded that the haemolysin YhlA plays an active role in the pathogenicity of $Y$. ruckeri. This effect is very likely related to its cytopathic activity and, perhaps, to its contribution to the acquisition of iron from the host cells. The expression of the $y h l B A$ genes is regulated by iron and temperature, which also modulates the production of ruckerbactin and the protease Yrp1. Even so, further studies are needed to unveil the regulatory cascades involved in the induction of virulence genes in this micro-organism.

\section{ACKNOWLEDGEMENTS}

This study was supported by the Spanish MCYT (grants AGL20000869 and AGL2003-229). L.F. was the recipient of predoctoral fellowships from the MCYT and Universidad de Oviedo.

We thank J. Méndez for providing the blood for the haemolysin assays, and P. Solano for contributing to the experiments on cytotoxicity. We thank A. F. Braña and T. Fabek for critical reading of the manuscript.

\section{REFERENCES}

Austin, D. A., Robertson, P. A. W. \& Austin, B. (2003). Recovery of a new biogroup of Yersinia ruckeri from diseased rainbow trout (Oncorhynchus mykiss, Walbaum). Syst Appl Microbiol 26, 127-131.

Braun, V., Günter, H., Nuess, B. \& Tautz, C. (1985). Hemolytic activity of Serratia marcescens. Arch Microbiol 141, 371-376.

Brillard, J., Duchaud, E., Boemare, N., Kunst, F. \& Givaudan, A. (2002). The PhlA haemolysin from the entomopathogenic bacterium Photorhabdus luminescens belongs to the two-partner secretion family of haemolysins. J Bacteriol 184, 3871-3878.

Chain, P. S., Carniel, E., Larimer, F. W., Lamerdin, J., Stoutland, P. O., Regala, W. M., Georgescu, A. M., Vergez, L. M. \& other authors
(2004). Insights into the evolution of Yersinia pestis through whole-genome comparison. Proc Natl Acad Sci U S A 101, 13826-13831.

Deng, W., Burland, V., Plunkett, G., III, Boutin, A., Mayhew, G. F., Liss, P., Perna, N. T., Rose, D. J., Mau, B. \& other authors (2002). Genome sequence of Yersinia pestis. J Bacteriol 184, 4601-4611.

Fernández, L., Secades, P., López, J. R., Márquez, I. \& Guijarro, J. A. (2002). Isolation and analysis of a protease gene with an $A B C$ transport system in the fish pathogen Yersinia ruckeri: insertional mutagenesis and involvement in virulence. Microbiology 148, 2233-2243.

Fernández, L., López, J. R., Secades, P., Menéndez, A., Márquez, I. \& Guijarro, J. A. (2003). In vitro and in vivo studies of the Yrp1 protease from Yersinia ruckeri and its role in protective immunity against enteric red mouth disease of salmonids. Appl Environ Microbiol 69, 7328-7335.

Fernández, L., Márquez, I. \& Guijarro, J. A. (2004). Identification of specific in vivo-induced (ivi) genes in Yersinia ruckeri and analysis of ruckerbactin, a catecholate siderophore iron acquisition system. Appl Environ Microbiol 70, 5199-5207.

Fouz, B., Zarza, C. \& Amaro, C. (2006). First description of nonmotile Yersinia ruckeri serovar I strains causing disease in rainbow trout, Oncorhynchus mykiss (Walbaum), cultured in Spain. J Fish Dis 29, 339-346.

Hertle, R., Hilger, M., Weingardt-Kocher, S. \& Walev, I. (1999). Cytotoxic action of Serratia marcescens haemolysin on human epithelial cells. Infect Immun 67, 817-825.

Hirono, I., Tange, N. \& Aoki, T. (1997). Iron-regulated haemolysin gene from Edwardsiella tarda. Mol Microbiol 24, 851-856.

Konkel, M. E. \& Tilly, K. (2000). Temperature-regulated expression of bacterial virulence genes. Microbes Infect 2, 157-166.

Kotetishvili, M., Kreger, A., Wauters, G., Morris, J. G., Sulakvelidze, A. \& Stine, O. C. (2005). Multilocus sequence typing for studying genetic relationships among Yersinia species. J Clin Microbiol 43, 2674-2684.

Litwin, C. M. \& Calderwood, S. B. (1993). Role of iron in regulation of virulence genes. Clin Microbiol Rev 6, 137-149.

Mahan, M. J., Tobias, J. W., Slauch, J. M., Hanna, P. C., Collier, R. J. \& Mekalanos, J. J. (1995). Antibiotic-based selection for bacterial genes that are specifically induced during infection of a host. Proc Natl Acad Sci U S A 92, 669-673.

Mekalanos, J. J. (1992). Environmental signals controlling expression of virulence determinants in bacteria. J Bacteriol 174, 1-7.

Miller, J. H. (1972). Experiments in Molecular Genetics, p. 354. Cold Spring Harbor, NY: Cold Spring Harbor Laboratory.

Palmer, K. L., Goldman, W. E. \& Munson, R. S. (1996). An isogenic haemolysin-deficient mutant of Haemophilus ducreyi lacks the ability 
to produce cytopathic effects on human foreskin fibroblasts. Mol Microbiol 21, 13-19.

Poole, K., Schiebel, E. \& Braun, V. (1988). Molecular characterisation of the haemolysin determinant of Serratia marcescens. J Bacteriol 170, 3177-3188.

Reed, L. J. \& Muench, H. (1938). A simple method of estimating fifty percent endpoints. Am J Hyg 27, 493-497.

Romalde, J. L. \& Toranzo, A. E. (1993). Pathological activities of Yersinia ruckeri, the enteric redmouth (ERM) bacterium. FEMS Microbiol Lett 112, 291-300.

Romalde, J. L., Conchas, R. F. \& Toranzo, A. E. (1991). Evidence that Yersinia ruckeri possesses a high affinity iron uptake system. FEMS Microbiol Lett 80, 121-126.

Romalde, J. L., Magariños, B., Barja, J. L. \& Toranzo, A. E. (1993). Antigenic and molecular characterization of Yersinia ruckeri: proposal for a new intraspecies classification. Syst Appl Microbiol 16, 411-419.

Sambrook, J. \& Russell, D. (2001). Molecular Cloning: a Laboratory Manual, 3rd edn. Cold Spring Harbor, NY: Cold Spring Harbor Laboratory.
Schiebel, E., Schwarz, H. \& Braun, V. (1989). Subcellular location and unique secretion of the hemolysin of Serratia marcescens. J Biol Chem 264, 16311-16320.

Schönherr, R., Tsolis, R., Focareta, T. \& Braun, V. (1993). Amino acid replacements in the Serratia marcescens haemolysin ShlA define sites involved in activation and secretion. Mol Microbiol 9, 1229-1237.

Simon, R., Priefer, U. \& Pühler, A. (1983). A broad host range mobilization system for in vivo genetic engineering: transposon mutagenesis in gram negative bacteria. Bio/Technology 1, 784-791.

Straley, S. C. \& Perry, R. D. (1995). Environmental modulation of gene expression and pathogenesis in Yersinia. Trends Microbiol 3, 310-317.

Strauss, E. J., Ghori, N. \& Falkow, S. (1997). An Edwardsiella tarda strain containing a mutation in a gene with homology to $s h l B$ and $h p m B$ is defective for entry into epithelial cells in culture. Infect Immun 65, 3924-3932.

Williams, M. L. \& Lawrence, M. L. (2005). Identification and characterisation of a two-component haemolysin from Edwardsiella ictaluri. Vet Microbiol 108, 281-289.

Edited by: S. C. Andrews 